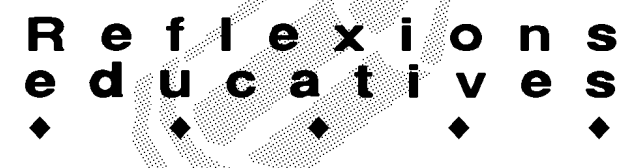

\title{
L'ESCOLA NORMAL DEL MAGISTERI PRIMARI DE TARRAGONA DURANT LA SEGONA REPÚBLICA (1931-1936). PRIMERA APROXIMACIÓ
}

\author{
Cristina Magriñà Salvat. Llicenciada en Història. URV
}

\begin{abstract}
Precedents
El treball d'investigació L'Escola Normal de Tarragona (1931-1939), defensat el novembre del 2001 davant el tribunal únic del programa de doctorat "Projecte Europeu" de la Universitat Rovira i Virgili, esdevé un dels eixos fonamentals de la tesi doctoral en la qual estic treballant, i de les quals he extret alguns detalls que tot seguit exposaré.
\end{abstract}

El 8 de març de 1839 es creava l'Escola Normal Central a Madrid, la primera a l'Estat espanyol, prosseguint d'aquesta manera l'obra endegada pels francesos amb la Llei Lakanal de l'any 1798. El 15 d'octubre de 1843 es publicava el primer reglament d'Escoles Normals (DE GUZMAN, 1971) i s'iniciva un pas important en el camí cap a la normalització de la formació del magisteri espanyol sota la influència de la reforma educativa dels liberals. El 19 de febrer d'aquest mateix any obria les portes l'Escola Normal de Mestres de Tarragona, situada a l'antic convent dels franciscans, la direcció de la qual requeia en Joaquim Benet i Maixé (actualment, aquest edifici alberga l'Arxiu Històric de la ciuat, situat a la Rambla Vella). Amb tot, caldria esperar la promulgació de la llei del 9 de setembre de 1857, coneguda com a Ley Moyano, per copsar l'interès de la classe política d'aplegar en un sol corpus legislatiu les disposicions que l'havien precedit en matèria d'instrucció pública (CUESTA, 1994). Les noies veurien restringit el dret a accedir oficialment a la formació del magisteri fins a l'any 1862, any d'obertura de l'Escola de Mestres femenina de la ciutat. L'obertura fou promoguda en gran mesura pel director i professor de la Normal de Mestres, Carlos Yeves. Situada al carrer de la Nau en un primer moment, restarà fins a1931 en un pis del carrer Major. La direcció del centre s'encarregà a Clotilde Sánchez Giménez, que ocupà el càrrec fins al 1901. Recordem que la R.O. del 24 de febrer de 1858 donava llum verda a la creació d'una Normal Central de Mestres femenina a Madrid, tal com quedava explícit a I l'article 114 de la Llei Moyano.

Els estudis de mestre a l'Estat espanyol al llarg del segle XIX es veuran mancats d'un cert enfocament professional, i queden estancats en el sistema educatiu anomenat tradicional. Amb tot, resultaria difícil obviar en el transcurs d'aquest segle la influència exercida per la Institución Libre de Enseñanza (ILE), creada l'any 1876 i tutelada per Francisco Giner de los Ríos. La ILEoptava per una pedagogia renovada assentada en una nova visió de la societat, els pilars de la qual havien de ser la emancipación intelectual, educación científica y austeridad ética (NOGUERA, 1984). Aquest nou perfil pedagògic a l'Escola Normal de Tarragona fou transmès pel professor Alejandro de Tudela exercint la seva docència en aquest centre durant disset anys, i llegant entre d'altres, obres com Estudios pedagógicosi el Programa memorandum de Historia de la Pedagogía.

D'altra banda, cal recordar que a l'últim terç del segle XIX va iniciar-se la renovació en el camp de la pedagogia. Pedagogs nord-americans -Dewey és un dels seus màxims representants-, i l'Institut Rousseau en el continent europeu, plantejaren una alternativa al model d'escola tradicional: L'Escola Nova.. Catalunya en aquest context no en quedà pas al marge, ja que des de diferents sectors polítics i socials es qüestionava l'estructura educativa de finals del segle XIX. Tot i així, l'Estat espanyol no avançà en el tema escolar. Calgué esperar al període de la Mancomunitat (1914-1923) per fer realitat l'acollida d'aquests nous plantejaments per part de les institucions públiques: La Ponència encarregada d'organitzar els Estudis Normals de la Mancomunitat es va veure estroncada amb l'adveniment de l'aixecament militar de Primo de Rivera, deixant en un segon terme les problemàtiques fins aleshores plantejades en el si de l'escola.

\section{L'Escola Normal del Magisteri Primari de Tarragona en els anys de la República. Una perspectiva legal \\ El 14 d'abril de 1931 era proclamada la II República Espanyola, i amb ella s'iniciava una profunda tasca de regeneració en el si del sistema educatiu de l'Estat. L'aplicació de la reforma dels estudis de Magisteri, arran}




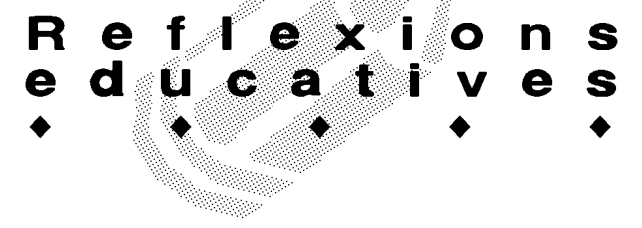

de la publicació del decret del 29 de setembre d'aquell mateix any, significà el trencament, a nivell teòric, amb els paràmetres pedagògico-educatius pels quals fins aleshores s'havia regit la formació del mestre a les escoles normals. El nou espectre educatiu havia de facilitar l'accés a la cultura a la nova societat, republicana, i per tant era necessària la creació de noves escoles, conseqüentment la formació del mestre havia d'assentarse en el nou model d'escola propugnat per l'ideari republicà: l'escola única, obligatòria i laica.

L'orientació professional del nou pla d'estudis evolucionaria en la dignificació del magisteri:

- Edat mínima d'ingrés a les escoles normals i amb l'exigència del títol de batxillerat.

- El pla es preveia realitzar en quatre anys acadèmics, amb un currículum diversificat en el qual es visualitzava l'aprenentatge de les metodologies específiques, l'últim dels quals era íntegrament destinat a la pràctica docent remunerada i amb accés directe a una plaça de l'escalafó del Magisteri oficial.

- La possibilitat d'especialització, a través dels Treballs d'especialització de tercer curs.

- La laïcitat i el règim de coeducació assumien la difícil papereta de convertir-se en factors cohesionadors en la creació d'aquest nou model de societat des de l'escola (Algunes d'aquestes propostes ja havien estat plantejades en la ponència encarregada d'organitzar els estudis Normals de la Mancomunitat: professionalització, especialització, prova d'ingrés, assaig coeducacional...).

Però tots aquests fenòmens, com es traduïren en l'evolució interna de l'Escola Normal de Tarragona en el transcurs dels anys 1931-1936?

L'octubre de 1931 s'iniciava un nou curs acadèmic a la plaça del Artillers, des d'on ja feia alguns anys es trobava situada l'antiga Escola de Mestres de Tarragona. Prèviament, s'havia procedit a la fusió dels claustres de professors de les Normals de nois i de noies. El local presentava una capacitat més aviat reduïda, ja que s'hi aplegaven alumnes de tres plans d'estudi diferents: els del Pla Professional de 1931, els del Pla Preparatori -pla transitori de tres anys de durada per als alumnes que volien ingressar al Pla professional i no tenien el títol de batxillerat- i els del pla 1914, a extingir. El mal estat de les infraestructures escolars es convertí en una qüestió recurrent a les sessions de claustre i a la premsa local, i aquest fet esdevingué en més d'una ocasió una picabaralla política (Arxiu Escola Normal de Tarragona -AENT-: Llibre d'Actes del Claustre 1931-1936. Sessió del 23/10/1931). S'hagué d'esperar fins a l'octubre de 1934 per consumar la viabilitat del projecte de construcció d'un nou centre vora la platja del Miracle, amb el qual es feien realitat les demandes que des de 1928 s'havien realitzat insistentment.

Des del punt de vista de les disposicions legals endegades pel Ministeri d'Instrucció Pública i Belles Arts -creat el 1901, el gabinet ministerial de l'any 1931 estava encapçalat pel tarragoní Marcel-lí Domingo, acompanyat per Rodolf Llopis i Domingo Barnés-, l'evolució interna de l'escola presentà dues etapes força diferenciades: d'una banda, el bienni 1931-33, en el qual la dinàmica interna del centre es dirigí bàsicament a posar en marxa el nou Pla d'estudis Professional; i de l'altra, el bienni 1934-36. El període 1931-33, coincidint amb els anys de govern progressista, s'encetava amb l'elecció de Miguel Sancho Barreda com a nou director del centre, càrrec que ja havia exercit amb anterioritat a l'antiga Normal de Mestres. L'Ordre de la Direcció General del 30 d'octubre de 1931 sobre reestructuració dels claustres normals concretava el nou esperit reformista amb l'entrada en aquest òrgan de govern d'un professor auxiliar per secció i el representant d'un alumne per curs de cadascun dels tres plans en vigència. L'alumne de primer curs del Pla Professional, Bernardo Casanova, es convertiria en el primer representant el curs 1932-33 (Llibre d'Actes del Claustre 1931-1936. Sessió 24/11/1932).

El Reglament d'Escoles Normals de 17 d'abril de 1933 significà que aquestes mesures es veiessin retallades fins al punt d'excloure l'alumnat del claustre. Pel que fa al professorat auxiliar, Josep Perelló en seria el seu únic representant. El canvi de direcció que establia la nova normativa fou criticat durament pel sector progressista del professorat, representat per les professores Elisa Uriz i Montserrat Bertran i el professor de música Josep Gols, amb el suport de l'alumnat, que era el qui realment en sortia més perjudicat. En canvi, els professors Francisco Manuel Nogueras, Josep Perelló i Juan Ribera s'hi mostraren totalment d'acord. Amb tot, el 8 de novembre d'aquest mateix any Antonio Orozco, alumne del Pla Professional, tornava a entrar al Claustre en representació del conjunt d'estudiants del centre, veient aquests restablert el dret a ésser representats en els òrgans de govern, tot i que parcialment. Aquest reglament exigia també posar en marxa la Junta de Govern, que venia a ésser com una mena de consell executiu de l'escola, que es feia càrrec del règim econòmic i que estava integrat pel director, la secretària Luisa Alonso i tres professors per elecció, que en aquest cas foren Laura Miret, Josefa Pérez i Francisco Manuel Nogueras.

Les mesures endegades en aquests primers anys que causaren més impacte a l'opinió pública de la ciutat, desencadenant un intens debat polític, foren el decret 


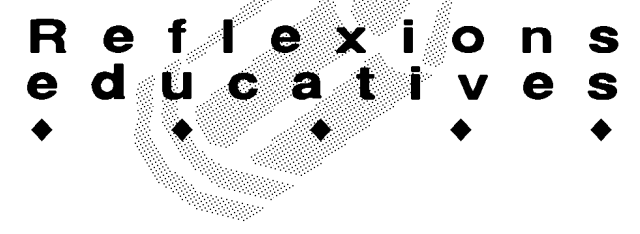

sobre el bilingüisme, que preveia l'establiment de les càtedres de Català a les Normals del principat, tot i que el català no era reconegut com una assignatura troncal del currículum.

Un segon aspecte conflictiu va ser la jubilació forçosa del professor Pedro Loperena (Llibre d'Actes del Claustre 1931-1936); tot i que les causes són força confuses i mereixedores d'una anàlisi més exhaustiva de les fonts, es convertí en un cas aïllat a les normals catalanes -d'un total de 33 jubilacions tramitades en el conjunt de l'Estat, segons el Decret del 2 de setembre de 1932, pel qual es jubilava el professorat de les Normals, en resposta a la reducció de plantilla deguda a la fusió d'aquests centres uns mesos abans (MORENTE, 1997)-. El seu reingrés es feia efectiu a mitjans del curs 1934-35, amb l'entrada en vigència de les noves directrius del govern radical-cedista.Tot sembla apuntar que els criteris seleccionats tingueren a veure amb el posicionament ideològic del professor en qüestió, ja que en el transcurs de la depuració empresa per les comissions depuradores a partir del juliol de 1936 se'n perdé la pista.

Un tercer aspecte que afectà l'escola va ser la promulgació a les Corts de la Llei de Congregacions i Associacions Religioses, que les suprimia, la qual cosa provocà un intens debat en la societat espanyola, fentnos pensar que la comunitat normalista tarragonina no restà al marge. No era gens rar llegir a la premsa local de l'època l'enfrontament diàlectic entre els alumnes del centre. Una nota anònima que publicava el Diari de Tarragona el 17 de març de 1932 deia: "...la maniobra iniciada, entre els estudiants de la Normal afectes als col.legis religiosos, per alguns elements extremistes que les inciten a presentar al claustre de professors un escrit, demanant que siguin festius els dies de la Setmana Santa". (Diari de Tarragona. 17/03/1932).

Un quart aspecte que cal tenir en compte va ser la problemàtica plantejada per la convivència de tres plans d'estudis diferents per a l'ensenyament de mestre. El Pla Professional de 1931 nasqué un pèl coix, ja que aquells alumnes que no comptaven amb el títol de batxiller i volien cursar el nou pla d'estudis havien de matricular-se en un pla-pont anomenat Cultural, i després realitzar una prova d'ingrés. Tan sols un 34\% dels alumnes matriculats en aquest pla l'any 1931 van decidir continuar amb els estudis, la resta optà majoritàriament per l'ensenyament privat. D'altra banda, era obvi que no podien quedar penjats els alumnes del pla de 1914.

Aquest batibull de plans d'estudi desembocà en un seriós enfrontament d'interessos entre un alumnat tan diversificat, provocant al llarg del període analitzat diversos actes de protesta, molts dels quals tingueren el seu suport a nivell estatal. D’aquesta manera, el març de 1934, els alumnes del Pla de 1914 comunicaven a la direcció de l'escola "que han acordado de abstenerse de entrar en clase a partir del día 15 del corriente, hasta que una disposición renueve favorablemente las siguientes bases (...): - Que todos los maestros que ingresen en el magisterio Oficial, ya sea perteneciendo al plan Profesional ya sean del plan de 1914, lo hagan por los últimos. -Convocatoria de cursillos de ingreso al Magisterio oficial anualmente tras la total extinción del plan de 1914 , destinando e/30\% de las plazas vacantes. -Sueldo mínimo de 4000 pesetas"(AENT: Entrades de correspondència,15/03/1934). La reforma del nou pla d'estudis no estava pas mal encaminada, ja que es preveia que en el curs 1934-35 s'haurien extingit el pla antic i el Cultural, i es deixaria pas lliure al Professional. La realitat dels fets no seguí fidelment aquesta dinàmica, topant d'altra banda amb els excessius canvis en la política educativa propiciada pels canvis de govern i l'adveniment, a partir de juliol de 1936, de l'aixecament militar, fets que impossiblitaren en gran mesura que s'apliqués el que s'havia considerat el millor pla d'estudis de Magisteri fins que no fou reconegut com un ensenyament universitari.

Els posicionaments irreconciliables al claustre i el descontentament de l'alumnat vers la gestió dels òrgans de govern -cal advertir que a partir del curs 1933-34 la disciplina i el control de les associacions d'alumnes normalistes es convertiren en una pràctica habitual (AENT: Llibre d'Actes del Claustre 1931-1936. Sessió 11/04/1934. També cal veure còpia del "Reglamento de Asociación de Normalistas del Plan Professional")-, s'aguditzarien a partir de novembre de 1933 amb la reorientació de la política educativa vers l'escola tradicional, propiciada pel canvi en el govern del partit republicà per la coalició radical-cedista. Possiblement les propostes més restrictives per descontextualitzar la reforma engegada l'any 1931 van ser:

- L'intent de suprimir el règim de coeducació. Al respecte el director, Miguel Sancho, feia constar "que en esta Escuela se ha practicado en toda amplitud el sistema coeducativo. Durante ese tiempo, el Director que suscribe no pudo consignar ningún inconveniente ni en la marcha de los estudios ni en ningún aspecto del desenvolvimiento de la vida académica; en cambio ha podido observar que la influencia de las señoritas en el porte, trato social, indumentaria de los alumnos, ha sido decisivo"(AENT: Sortides de correspondència 10/06/1936), aspecte que prefigurava que tothom anava més arreglat i que el tracte entre nois i noies sovintejà.

- La supressió del títol de batxillerat per a ingressar 


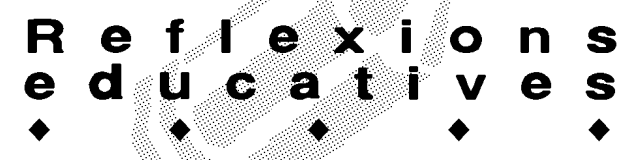

a les Escoles Normals (AENT: Llibre d'actes del Claustre 1931-1936. Sessió 2/03/1934).

- Modificació del Decret sobre Bilingüisme que preveia que l'ensenyament del català i del castellà havia de donar-se indistintament des de pàrvuls fins als 8 anys, i a partir dels vuit anys ampli predomini del castellà fins a arribar al coneixament complet d'aquesta llengua (AENT: Llibre d'Actes del Claustre 1931-1936. Sessió Extraordinària 19/ 12/1934).

Els nous plantejaments pedagògico-educatius proposats pels nous governants coincidiren amb la reivindicació, per part d'un sector del professorat -entre ells cal destacar Montserrat Bertran, professora de Pedagogia i de Català-, i una part important de l'alumnat vers l'ensenyament de la Llengua Catalana al centre. Tot i que el curs 1931-1932 s'hi va fer un curs de català que, com indicà un alumne de l'escola, es tractà més aviat "d'un tímid assaig, un curset de gramàtica catalana" (Diari de Tarragona, 25/05/1932), s'hagué d'esperar fins a mitjans del curs 1933-34 perquè el claustre proposés al Rectorat la designació de Montserrat Bertran per encarregar-se de les classes de català. Aquesta situació era estranya si considerem que ja feia més de dos anys que s'havia aprovat el decret sobre la cooficialitat de la Ilengua catalana, i que el 9 de setembre de 1932 l'Estatut d'Autonomia l'havia ratificat. Aquestes incongruències saltaren els murs de l'escola per fer-se'n ressò els òrgans de premsa de la ciutat amb pretextos com "La persecució del catalanisme a l'Escola Normal de Tarragona"o "Les anormalitats de la Normal" (Diari de Tarragona i La
Cruz, estiu 1934), en els quals s'acusava la secretària i professora del centre, Luisa Alonso, i al director d'impedir la normalització d'aquest ensenyament amb procediments avaluadors injustos vers aquells alumnes que sentien simpatia vers la cultura catalana, o posant traves a l'hora d'expedir els certificats de català, o bé amb la prohibició de l'himne dels Segadors el dia de la festa del llibre.

Per ara, resulta difícil apuntar fins a quin punt la tasca pedagògica es veié afectada per les incidències esmentades. Sembla que l'estat deplorable de les instal-lacions del centre impedien posar en pràctica les exigències del nou pla d'estudis, a més de l'enfrontament ideològic en el si del claustre de professors del centre, que obstaculitzava la viabilitat d'una profunda regeneració dels estudis de magisteri almenys a l'escola Normal de Tarragona.

\section{Referències bibliogràfiques}

CUESTA ESCUDERO, P. La escuela en la reestructuración de la sociedad española (1900-1923). Siglo XXI de España Editores, S.A. Madrid.1994. Pàg. 10-12.

DE GUZMAN, M. Cómo se han formado los maestros. Cien años de disposiciones oficiales (1871-1971). Edit. Prima Luce. Barcelona. 1973. Pàg.13.

MORENTE VALERO, F. La Escuela y el Estado Nuevo. La depuración del Magisterio Nacional (1936-1943). Edit. Ambito. Barcelona. 1997. Pàg.46.

NOGUERA ARROM, J. La Escuela Normal de Tarragona (1843-1931), cien años de la vida de una Escuela Normal. Edit. Universitat de Barcelona, 1984. Pàg.102.

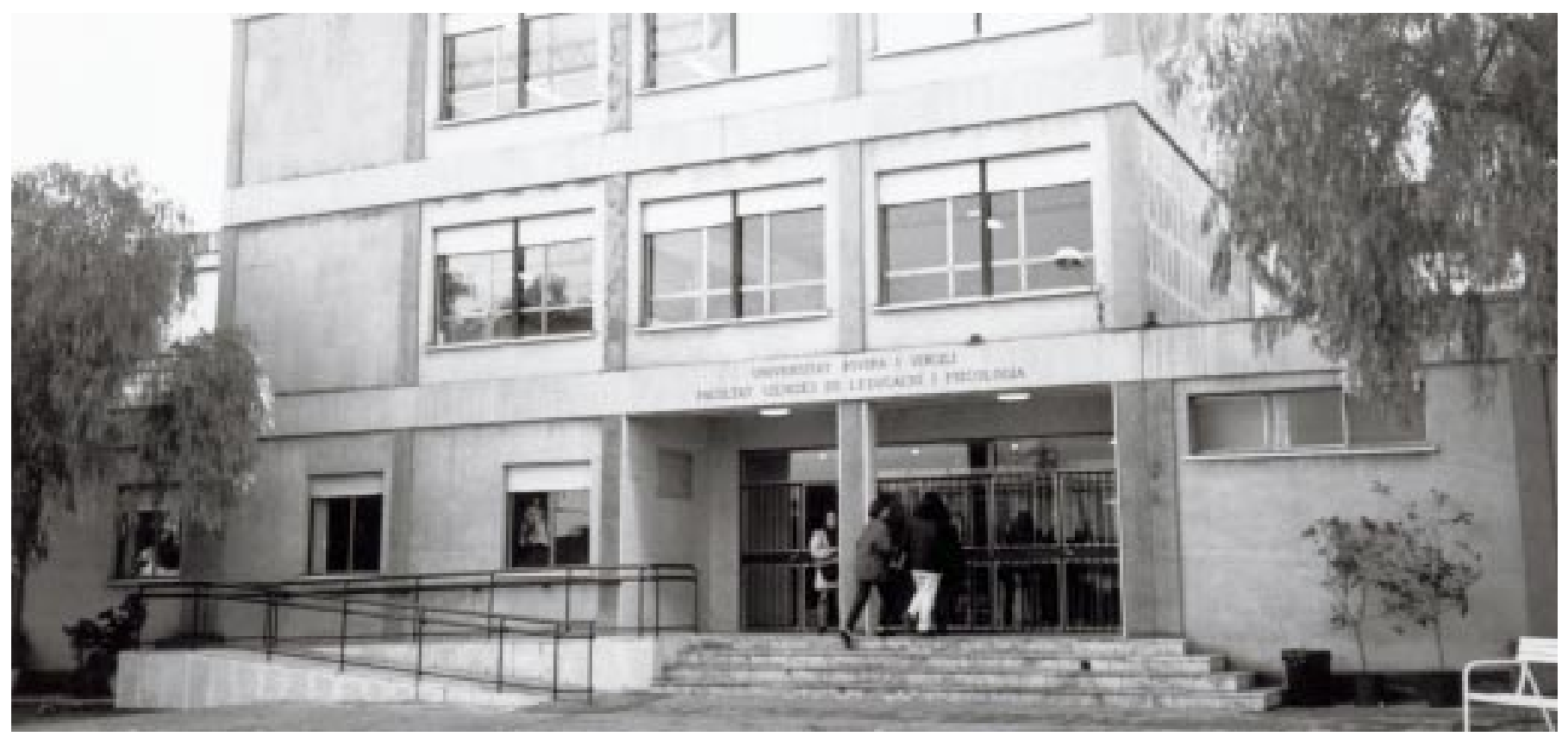

